\title{
Market Power in the Spanish
}

\author{
Electricity Auction.*
}

\author{
Aitor Ciarreta ${ }^{\dagger}$ and María Paz Espinosa ${ }^{\ddagger}$
}

December 2004

\begin{abstract}
We use hourly bid data from the Spanish day-ahead electricity auction to obtain a lower bound measure of generators' market power. Our method is not based on cost estimates but rather on the different behavior of strategic generators as compared to the behavior of more competitive producers. The results indicate that, despite the price cap effect of regulation in this market, the larger operators in the day-ahead market are able to increase prices above the competitive benchmark by a significant amount.
\end{abstract}

JEL: L11, L13, L51

Keywords: market power, electricity market

*Financial support from Ministerio de Ciencia y Tecnología (BEC2003-02084), UPV (9/UPV 00035.321-13560/2001), Fundación BBVA and IVIE is gratefully acknowledged. We thank Jorge de la Cruz for his very helpful research assistance, and seminar participants at the IDEI Conference on Competition and Coordination in the Electricity Industry (Toulouse), Universidad Autónoma de Barcelona and Universidad de Alicante for their comments. Natalia Fabra and Matilde Machado provided useful suggestions. We are especially indebted to Eva Ferreira, M. Cruz Loyo and Enrique Pastor for their invaluable help.

${ }^{\dagger}$ Universidad del País Vasco. Departamento de Fundamentos del Análisis Económico II. Avenida Lehendakari Aguirre 83, 48015 Bilbao, Spain. e-mail: jepciana@bs.ehu.es

$\ddagger$ (corresponding author) Universidad del País Vasco. Departamento de Fundamentos del Análisis Económico II. Avenida Lehendakari Aguirre 83, 48015 Bilbao, Spain. e-mail: jepesalp@bs.ehu.es 


\section{Introduction}

The Spanish spot market for electricity was introduced in $1998 .{ }^{1}$ Since then, centralized spot markets have been abolished in several places, including California, and England and Wales. It has been argued that the problems in these electricity markets were due to market power coupled with a tight demand-supply balance (see Green, 2001). ${ }^{2}$ In this paper we explore whether the auction rules and other market conditions in the Spanish wholesale market alow the larger operators to exploit their market power.

A high concentration index together with an inelastic demand suggest that firms will use their market power to set prices well above marginal costs. However, depending on other market conditions, regulation or electricity auction rules, concentration may give rise to higher or lower margins. Wolfram (1999) found that for the British market, prices were much closer to marginal cost than most theories predicted, although she also finds some evidence of strategic capacity withholding. Explanations for the restrained price levels were financial contracts between the suppliers and their customers, ${ }^{3}$ threat of entry, and threat of regulatory intervention in the market. ${ }^{4}$

In the industrial organization literature several methods have been used to measure market power in electricity markets. Mount (2001) associates systematic patterns of price spikes with market power use in the UK electricity market.

\footnotetext{
${ }^{1}$ Regulated by Act 2019 of December 26, 1997.

${ }^{2}$ See Fabra (2001) for an overview of the literature on electricity markets and empirical evidence.

${ }^{3}$ See Green (1999) on contracts for differences.

${ }^{4}$ However, Newbury (2002) argues that many European countries lack the necessary regulatory power to mitigate generator market power.
} 
Spear (2003) argues that horizontal market power explains price spikes in peak periods observed in the California generation market, as well as the reduction in additions to capacity. Several papers (Green (1994), von der Fehr and Harbord (1993), Borenstein, Bushnell and Wolak (2000) and Wolfram (1999), among others) have used direct measures of marginal cost to calculate price cost margins. Macatangay (2002) proposes a test of "suspicious patterns" of bidding behavior based on the slopes of the supply curves; he shows that "suspects" behave differently from the rest and checks whether the strategies of the suspect firms affect one another. Bushnell and Saravia (2002) measure the competitiveness of the New England electricity market by comparing equilibrium prices with a competitive benchmark: an estimate of the price that would result if no firm exerted market power. They obtain a demand-weighted markup from $4 \%$ to $12 \%$ depending on whether equilibrium prices include operating constraints or not. $^{5}$

Our approach is different from previous work measuring the impact of market power in that we do not use cost estimates. Rather, we study the actual behavior at the electricity auction of firms with high market share and compare it to that of small firms. ${ }^{6}$ The bid of a large operator at the pool is obtained by aggregating the bid schedules of each generating plant under its control. In the absence of any market power (that is, in the competitive benchmark), a generating plant would bid at the pool independently of whether it belongs to a large operator or to a small firm, and thus the bid function of a larger operator

\footnotetext{
${ }^{5}$ In the Inudstrial Organization literature there is a long tradition of price-cost measurement. See for example Rosse (1970), Bresnahan (1981, 1987) and Nevo (2001).

${ }^{6}$ In what follows we consider that the size of a generator is its capacity.
} 
would coincide with the bid schedule obtained as the sum of the bids of similar plants under the control of small firms. Of course, in real auctions production units will take into account their effect on other production plants under the same ownership and will respond to their incentive to restrict output and raise prices when calculating their optimal bid schedule. Larger generators are very often marginal bidders at the auction, determining the price that is paid to all plants for all units sold. This impact on equilibrium prices creates an incentive to offer plant's bids schedules which are to the left of the equivalent bids of small generators. Our measure of market power is based on this difference in bids between larger and smaller operators at the pool.

It is worth noting that, compared to previous works based on price-cost margin estimates, our method provides a lower bound for that margin. In other words, our competitive benchmark is a situation in which each plant is run independently (and the equilibrium price that would be determined in that case) but, as long as the number of plants is finite, each plant could bid above marginal cost. ${ }^{7}$ This method may be useful whenever cost data are not available.

Our main findings for the Spanish pool are that the two larger operators consistently submit bid curves which are to the left (higher prices for every quantity bid) of the competitive benchmark. We also calculate the increase in price-cost margins for peak and off-peak hours. These results are somewhat consistent with those of Wolfram (1998) who finds evidence that in the British market the larger supplier submitted higher bids for similar plants.

\footnotetext{
${ }^{7}$ This is the case if we model the wholesale market as Cournot competition or as competition in supply curves.
} 
Besides market concentration and the electricity auction rules, there are other features of the market which could potentially affect firms' incentives for price setting. The market is vertically integrated, so that larger generators are also large buyers in this market. This feature might moderate the real incentives for firms to keep pool prices high. ${ }^{8}$ We also examine how regulation concerning stranded costs payments (CTCs) affects bidding behavior.

The paper is organized as follows. Section 2 gives a very brief description of the Spanish pool. In Section 3 we define a measure of a generator's market power, based on the impact that its bidding has on the equilibrium price: if all the plants of a generator were run independently, we would obtain an equilibrium price; when these plants coordinate their bids, the equilibrium price is higher. This price difference yields a measure of market power. The rest of the paper presents our empirical results for the Spanish pool. In Section 4 we describe our competitive benchmark and the procedure for measuring each firm's market power and in Section 5, we show the statistical results. Section 6 concludes.

\section{The Spanish wholesale electricity market}

The Spanish pool for electricity (day-ahead market) started its operations in January 1998 organized a s a uniform-price auction. ${ }^{9}$ Two companies, Endesa (EN) and Iberdrola (IB), own the majority of generating capacity, while Unión Fenosa (UF) and Hidrocantábrico (HC) are smaller competitors; all are private

\footnotetext{
${ }^{8}$ See Kühn and Machado (2004) for an analysis of vertical integration in the Spanish wholesale market.

${ }^{9}$ After Act 54/1997 liberalizing the market was approved in November 1997 and Act 2019/1997 established the rules of the production market.
} 
companies and each owns nuclear, thermal plants and hydroelectric units. At the beginning of 2002, EN sold a small part of its capacity (Viesgo) to the Italian company ENEL, which has become the fifth competitor in this market. During 2002 and 2003 there has been entry in small scale (Repsol, Gas Natural,...).

The pool works as follows. Before 11:00 a.m., qualified buyers and sellers of electricity present their offers for the following day. Each day is divided into 24 hourly periods.

Sellers in the pool present selling bids consisting of up to 25 pairs of different prices and the corresponding energy quantities for each of the 24 periods and for each generating unit they own; the prices must be increasing. ${ }^{10}$ If no restriction is included in the offer this is called a 'simple offer'. A seller may also present a 'complex offer' which may include indivisibility conditions, a minimum revenue condition, production capacity variation (load gradient conditions) and scheduled stop conditions. The pool administrator consolidates the sales bids for each hourly period to generate an aggregate supply curve.

Qualified buyers in the pool present purchasing bids. ${ }^{11}$ They state a quantity and a price of a power block and there can be as many as 25 power purchasing blocks for the same purchasing unit, with different prices for each one; the prices must be decreasing. The pool administrator constructs an aggregate demand

\footnotetext{
${ }^{10}$ According to the Electricity Market Activity Rules, p. 6, generators "shall be required to submit electric power sale bids to the market operator for each of the production units they own for each and every one of the hourly scheduling periods." There is an exception to this rule when the production unit has a bilateral contract which, due to its characteristics, is excluded from the bidding system.

${ }^{11}>$ From January 1st 2003 , all buyers of electricity are considered qualified buyers. Before that date qualified buyers were those with consumption greater or equal to $1 \mathrm{GWh}$ per year. The required consumption has decreased over time from $5 \mathrm{GWh}$ (December 1998) to 3GWh (April 1999), to 2GWh (July 1999) and to $1 \mathrm{GWh}$ (October 1999).
} 
with these offers.

In a session of the daily market the pool administrator combines these offers matching demand and supply for each of the 24 hourly periods and determines the equilibrium price for each period (the system marginal price) and the amount traded. ${ }^{12}$ This matching is called the base daily operating schedule $(P B F)$. After the base daily operating schedule is settled, the pool administrator evaluates the technical feasibility of the assignment; if the required technical restrictions are met then the program is feasible; if not, some previously accepted offers are eliminated and others included to obtain the provisional feasible daily schedule $(P V P)$. This reassignment ends at 14:00. By 16:00 the final feasible daily schedule $(P V D)$ is obtained taking into account the ancillary services assignment procedure. There is also an intra-day market to make any necessary adjustments between demand and supply. ${ }^{13}$ The result is called the final hourly schedule (PHF).

\section{A measure of market power}

Our main interest is to provide a measure of market power independent of cost estimates. The basic idea is to compare the bidding behavior at the auction of players with a large capacity, to the bidding behavior of small players. In the presence of market concentration, most models would predict prices above

\footnotetext{
${ }^{12}$ Appendix 1 describes the procedure for calculating the system marginal price when demand and supply intersect in a vertical or horizontal section of either the aggregate demand or the aggregate supply curves.

${ }^{13}$ The intra-day market started working in April 1998. In the first three months it had 2 sessions per day. From July 1998 it had 4 sessions per day and from September 1998 it had 5 sessions. Now it has at least 6 sessions.
} 
marginal cost. This is the case when the spot market is modeled as supply function competition (Klemperer and Meyer, 1989; Green and Newbery, 1992; Bolle, 1992; Green, 1996; Grant and Kahn, 2000) or as Cournot competition (Borenstein and Bushnel, 1997). ${ }^{14}$ The market has also been modelled as a multi-unit auction (Fabra, von der Fehr and Harbord, 2002, von der Fehr and Harbord, 1993, Wolfram, 1999); market power may be also present in equilibrium in these multiunit auction models. ${ }^{15}$ García-Castro and Marín (2003) have modeled the Spanish pool (decreasing demand and short-lived bids) using auction theory and obtained equilibria in pure strategies with prices above marginal cost. Thus, even though the results of the existing models differ, they all capture the same phenomenon: the higher incentives of large generators to restrict output as compared to the incentives of smaller generators. Based on this difference we derive an index of market power which is a lower bound for the Lerner index. Then we will measure such an index with Spanish pool data and test for differences in bidding behavior.

The standard measure of market power is the Lerner index (Lerner, 1934): $\frac{p-c}{p}$, where $c$ is marginal cost. In this section we propose a measure of market power which is a lower bound for the Lerner index. Thus, if we find that market power is significant according to our index, we can be sure that $\frac{p-c}{p}$ is also significant. The measure is based on the comparison of a generator's behavior, referred to a particular production unit, to the behavior of a generator who owns only one production unit. If a plant from a larger generator were to bid

\footnotetext{
${ }^{14}$ For a discussion of the advantages of the supply function equilibrium model over Cournot, see Baldick, Grant and Kahn (2000).

${ }^{15}$ See for example von der Ferh and Harbor, 1993, p. 537.
} 
the same bid curve as a plant from a generator with only one plant, then it would not be using its market power associated with size. However, we would expect a larger generator to instruct its plants to restrict output, submitting bid schedules to the left. Any difference between the two bid curves will be attributed here to market power and the impact on equilibrium prices will be used to construct a measure of individual market power.

More precisely, for a generator $i$ with $m$ plants we define a synthetic generator $i$ as a generator which does not maximize joint profits for the $m$ plants, rather it instructs each plant to present a bid curve at the pool so as to maximize the plant's profits. In other words, a synthetic generator does not internalize the effects of its plants on each other's profits, i.e. it does not fully exploit its market power. Our measure of market power is based on the comparison of a generator's equilibrium behavior, referred to a particular production unit, to the equilibrium behavior of a generator who owns only one production unit.

Denote $S_{i}$ the bid schedule of generator $i$, obtained from the sum of all its plants' bid schedules, $S_{i}=\sum_{h=1}^{m} S_{i h}$.

Similarly, we denote $S_{i}^{s}$ the bid schedule of synthetic generator $i, S_{i}^{s}=$ $\sum_{h=1}^{m} S_{i h}^{s}$ where $S_{i h}^{s}$ would be the bid of plant $h$ were plant $h$ to maximize its profits disregarding other plants under the same ownership.

Denote $D_{t}(p)$ the demand function and $p_{t}$ the equilibrium price at the pool at time $t$. This price is the market clearing price so that $D_{t}(p)=\sum_{i=1}^{m} S_{i}(p)$. Now, if we replace generator $i$ 's bid schedule by synthetic generator $i$ 's bid, $S_{i}^{s}(p)$, the equilibrium price would be different: $D_{t}\left(p^{i_{s}}\right)=S_{i}^{s}\left(p^{i_{s}}\right)+\sum_{j \neq i} S_{j}\left(p^{i_{s}}\right)$. The 


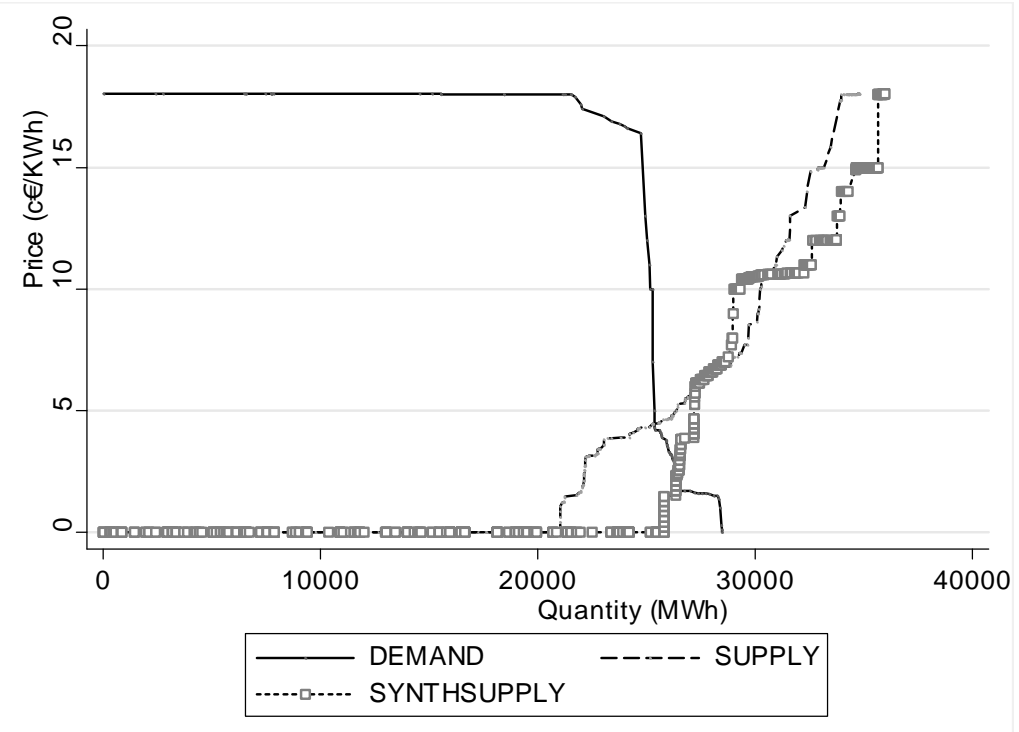

difference between the market clearing prices $p_{t}$ and $p_{t}^{i_{s}}$ is a measure of producer i's market power, its ability to raise prices.

If we replace the bid schedules from several generators we get a measure of joint market power. Denoting $p_{t}^{I_{s}}$ the market clearing price at time $t$ after replacing the bid schedule of producers in set $I$ by their synthetic bid, i.e. $D_{t}\left(p_{t}^{I_{s}}\right)=\sum_{i \in I} S_{i}^{s}\left(p_{t}^{I_{s}}\right)+\sum_{j \notin I} S_{j}\left(p_{t}^{I_{s}}\right)$, the difference $p_{t}-p_{t}^{I_{s}}$ measures their joint ability to raise pool prices. Figure 1 shows the observed demand schedule, observed supply schedule at the day-ahead market and synthetic supply schedule (both IB and EN bids have been replaced by their synthetic bids) for November 20th, 2001, at 12:00.

Our measure of market power of generator $i$ 's is then:

$$
M P_{i}=\frac{p-p^{i_{s}}}{p}
$$


and a similar definition for joint market power. This measure is a lower bound for the standard index of market power, $\frac{p-c}{p}$, since $p_{t}^{i_{s}}>c, p_{t}^{I_{s}}>c$, and it will be interpreted as such, rather than as the "true measure" of market power. An advantage of our procedure for measuring market power, with respect to other measures, is that it shows the contribution of asymmetric firms to the price-cost margin.

The measure should be interpreted as "sellers effective market power," that is, the extent to which a seller is having an upward effect on price. In empirical applications we may find firms with a large market share in generation but exerting a low impact on prices due to the presence of contracts for differences, vertical integration or regulation.

\section{Measuring market power in the Spanish pool}

We want to examine the effect of each firm's market power. The competitive benchmark is the bidding behavior at the pool of a generator who does not exercise any market power. Larger generators present bids for each unit that maximize joint profits for the firm. At the same auction, there are small generators with units of similar characteristics. We approximate the competitive behavior for a larger generator using the bids at the same auction of small generators. The two larger generators in the Spanish wholesale market are Endesa $(E N)$ and Iberdrola $(I B)$. Therefore, we first build a so-called "Synthetic En-

desa" $\left(E N^{s}\right)$ and a "Synthetic Iberdrola" $\left(I B^{s}\right)$. Then, we compare the auction 
outcome to the outcome obtained after replacing the bid schedules of the firms by the bid schedules of the synthetic firms.

First, we build the empirical bid functions of Endesa $(E N)$, Iberdrola $(I B)$, Unión Fenosa $(U F)$, Hidrocantábrico $(H C)$ and the rest of the firms, using hourly data. Then, we aggregate all of them to get the aggregate supply function, $S_{t}$, for each day and hour. Finally, we intersect the aggregate supply curve with the demand schedule, $D_{t}$, and compute the equilibrium price $p_{t}$ following the market operator's rules (see Appendix 1) The result is a time series of prices $p_{t}$.

The computed market clearing prices $p_{t}$ do not take technical restrictions into account. Technical restrictions should not represent a significant bias for the difference between prices and synthetic prices since they are.also ignored when we compute synthetic prices. ${ }^{16}$

Second, we use $U F, H C$ 's and other small generators' production units to build the synthetic Endesa $\left(E N^{s}\right)$ and the synthetic Iberdrola $\left(I B^{s}\right)$ in the following way. For each plant under the ownership of a large generator, plant $L$, we choose a plant using the same technology under the ownership of a small generator, plant $S$, and with a similar capacity. We compute a capacity coefficient dividing the capacity of plant $L$ over the capacity of plant $S: \frac{K_{L}}{K_{S}}$. We multiply the quantities in the bid by firm $S$ by the coefficient $\frac{K_{L}}{K_{S}}$, so as to get a 'scaled bid'. We replace the bid by plant $L$ by the 'scaled bid' by plant $S$. The bid so obtained is called the synthetic bid for plant $L$ (Appendix 2 presents

\footnotetext{
${ }^{16}$ In June 2002 , technical restrictions affected $1.08 \%$ of the volume in the daily market, and implied an increase on the average price in the daily market of just $0.065 \mathrm{cEur} / \mathrm{KWh}$.
} 
an example). Repeating this procedure for all the plants under the ownership of a large generator, and aggregating for all the firms we get the synthetic bid curves for the larger generators.

Then, in the aggregate supply we replace the original bid schedules of the large firms by the synthetic ones, and obtain a new aggregate supply denoted $S_{t}^{E N^{s}+I B^{s}}$. Intersecting this aggregate supply $S_{t}^{E N^{s}+I B^{s}}$ with the demand schedule $D_{t}$, the result is a time series of synthetic equilibrium prices, as they would have been if Endesa and Iberdrola had followed their synthetic bid schedules. This series of synthetic equilibrium prices is denoted $p_{t}^{E N^{s}+I B^{s}}$.

We can also repeat the procedure for each firm individually, to find the proportion of the equilibrium price variation which is due to each firm's market power. In this case we only replace the bid schedule by one of the large firms by its synthetic bid schedule, keeping all the rest constant. We obtain the equilibrium price when Iberdrola's bid is replaced by its synthetic bid: $p_{t}^{I B^{s}}$ and the corresponding price for Endesa: $p_{t}^{E N^{s}}$.

If neither of the large operators had any market power, $p^{E N^{s}+I B^{s}}=p$ that is, the time series $p_{t}^{E N^{s}+I B^{s}}$ and $p_{t}$ would only differ in the realization of a random term with zero mean. Under the alternative hypothesis, if the large generators had market power, then we should expect positive values for the difference $p-p^{E N^{s}+I B^{s}}>0$, which is the numerator of our measure of market power $M P$. Our empirical test is based on this implication. Under the null hypothesis $p_{t}$ and $p_{t}^{E N^{s}+I B^{s}}$ will only differ in the realization of a random error, while under the alternative, $p_{t}$ and $p_{t}^{E N^{s}+I B^{s}}$ will show a systematic difference. 
We extend this analysis to individual market power of the two larger generators and check whether $p^{E N^{s}}$ and $p^{I B^{s}}$ are different from $p$.

\section{Results}

The data consists of hourly demand and supply bids for each agent and for each production and demand unit, in the day-ahead electricity wholesale market, from May 2001 to December 2003. We do not consider the energy traded in the intra-day market, which amounts to less than $5 \%$ of the energy traded in the day-ahead market.

There are 23401 hours, 5881 corresponding to the period May 2001 to December 2001, and 8760 hours for each of the years 2002 and 2003. Hours are classified in peak, off-peak 1 and off-peak 2 hours (high, low and intermediate demand hours, respectively). ${ }^{17}$

We have computed the following time series: the market clearing prices, the synthetic prices obtained by replacing EN's bids by its synthetic bids, the synthetic prices obtained by replacing IB's bids by the synthetic bids, and finally the synthetic prices obtained by replacing both EN's bids and IB's bids by their respective synthetic bids: $\left(\mathrm{IB}^{s}+\mathrm{EN}^{s}\right)$ prices. Since the bids from nuclear plants are never the marginal bids at the auction, it is reasonable to think that

\footnotetext{
${ }^{17}$ Peak demand hours: From 16:00 to 22:00 week days (excluding holidays) in November, December, January, and February. From 9:00 to 15:00 week days in March, April, July, and October. Off-peak 1 demand hours: From 0:00 to 8:00 every day of the year, plus Saturdays, Sundays, and holidays. August is also included. Off-peak 2 demand hours: From 6:00 to 16:00 and from 22:00 to 00:00, week days in November, December, January, and February. From 8:00 to 9:00, and from 15:00 to 00:00, week days in March, April, July, and October. > From 8:00 to 00:00 week days in May, June, and September.
} 
plants with this technology are not being used strategically. Nevertheless, we tested whether the nuclear synthetic bids were different from the actual bids from nuclear plants. The data indicate that they are not statistically different, so that in the case of nuclear energy we have kept the actual bids instead of replacing them by the synthetic bids.

The supply bids at the auction sometimes include restrictions that may be binding. ${ }^{18}$ When that is the case, those bids are not included in the final assignment by the market operator, OMEL. Since these restrictions cannot be replicated for the synthetic bids we have decided to ignore them. Ignoring those restrictions sometimes causes our market clearing prices to be lower than the price made public by the market operator. Since the complex conditions on the supply bids are ignored both for the actual and the synthetic plants, there is no reason to think that this procedure is introducing any bias in the measurement of market power.

On the other hand, the market operator sometimes rejects demand bids at a high price because they are unfeasible given the capacity restrictions of the interconnections with the neighbor countries. In those cases, there is a rationing procedure to assign the interconnection capacity among bidders. This reduction on demand sometimes causes our market clearing price to be higher than the price published by OMEL. Again, these capacity limits are ignored both for the synthetic bids and for the actual ones so that no bias is introduced.

We present a test of unconditional means. The null is that market power

\footnotetext{
${ }^{18}$ A 'complex offer' may include indivisibility conditions (for the first block in the bid), a minimum revenue condition, load gradient conditions and scheduled stop conditions.
} 
is zero, so that market clearing prices are equal to synthetic equilibrium prices. We test this hypothesis for each of the larger firms and we also test whether joint market power is zero.

Results are reported in Table 1. We run the test considering all the observations, peak demand hours, off-peak 2 demand hours (intermediate demand levels), and off-peak 1 hours (low demand), for each of the hypotheses to be tested. 


\begin{tabular}{|c|c|c|c|c|c|}
\hline \multirow[b]{2}{*}{$\mathrm{c} € / \mathrm{kwh}$} & \multirow[b]{2}{*}{ Period } & \multirow[b]{2}{*}{ All Hours } & \multicolumn{3}{|c|}{ Type of Hour } \\
\hline & & & Peak & Off-peak 2 & Off-peak 1 \\
\hline \multirow{4}{*}{$\bar{P}-\bar{P}^{E N^{s}}$} & $2001-2003$ & $\begin{array}{l}\mathbf{0 . 1 4 3} \\
(0.004)\end{array}$ & $\begin{array}{c}0.3 \\
(0.018)\end{array}$ & $\begin{array}{c}0.223 \\
(0.009)\end{array}$ & $\begin{array}{c}0.072 \\
(0.005)\end{array}$ \\
\hline & 2001 & $\begin{array}{l}\mathbf{0 . 0 8 5} \\
(0.008)\end{array}$ & $\begin{array}{l}-0.159 \\
(0.044)\end{array}$ & $\begin{array}{c}0.097 \\
(0.013)\end{array}$ & $\begin{array}{c}0.114 \\
(0.009)\end{array}$ \\
\hline & 2002 & $\begin{array}{l}\mathbf{0 . 1 2 4} \\
(0.008)\end{array}$ & $\begin{array}{c}0.34 \\
(0.027)\end{array}$ & $\begin{array}{c}0.187 \\
(0.016)\end{array}$ & $\begin{array}{c}0.047 \\
(0.008)\end{array}$ \\
\hline & 2003 & $\begin{array}{c}\mathbf{0 . 2} \\
(0.007)\end{array}$ & $\begin{array}{c}0.496 \\
(0.026)\end{array}$ & $\begin{array}{l}0.335 \\
(0.01)\end{array}$ & $\begin{array}{c}0.069 \\
(0.007)\end{array}$ \\
\hline \multirow{4}{*}{$\bar{P}-\bar{P}^{I B^{s}}$} & $2001-2003$ & $\begin{array}{l}\mathbf{0 . 6 8 7} \\
(0.01)\end{array}$ & $\begin{array}{c}0.946 \\
(0.049)\end{array}$ & $\begin{array}{c}0.889 \\
(0.022)\end{array}$ & $\begin{array}{c}0.531 \\
(0.008)\end{array}$ \\
\hline & 2001 & $\begin{array}{l}\mathbf{0 . 5 3 7} \\
(0.023)\end{array}$ & $\begin{array}{l}0.040 \\
(0.136)\end{array}$ & $\begin{array}{c}0.758 \\
(0.050)\end{array}$ & $\begin{array}{c}0.492 \\
(0.019)\end{array}$ \\
\hline & 2002 & $\begin{array}{l}\mathbf{0 . 4 2 7} \\
(0.019)\end{array}$ & $\begin{array}{l}0.651 \\
(0.091)\end{array}$ & $\begin{array}{c}0.499 \\
(0.044)\end{array}$ & $\begin{array}{c}0.344 \\
(0.015)\end{array}$ \\
\hline & 2003 & $\begin{array}{l}\mathbf{1 . 0 4 6} \\
(0.009)\end{array}$ & $\begin{array}{c}1.688 \\
(0.034)\end{array}$ & $\begin{array}{c}1.365 \\
(0.019)\end{array}$ & $\begin{array}{c}0.745 \\
(0.009)\end{array}$ \\
\hline \multirow{4}{*}{$\bar{P}-\bar{P}^{E N^{s}+I B^{s}}$} & $2001-2003$ & $\begin{array}{l}\mathbf{0 . 7 7 2} \\
(0.012)\end{array}$ & $\begin{array}{l}1.085 \\
(0.054)\end{array}$ & $\begin{array}{c}1.027 \\
(0.023)\end{array}$ & $\begin{array}{l}0.577 \\
(0.01)\end{array}$ \\
\hline & 2001 & $\begin{array}{l}\mathbf{0 . 7 1 2} \\
(0.027)\end{array}$ & $\begin{array}{l}-0.116 \\
(0.153)\end{array}$ & $\begin{array}{c}0.959 \\
(0.058)\end{array}$ & $\begin{array}{c}0.702 \\
(0.025)\end{array}$ \\
\hline & 2002 & $\begin{array}{c}\mathbf{0 . 4 3 6} \\
17 \\
(0.021)\end{array}$ & $\begin{array}{l}0.779 \\
(0.094)\end{array}$ & $\begin{array}{l}0.563 \\
(0.049)\end{array}$ & $\begin{array}{l}0.299 \\
(0.019)\end{array}$ \\
\hline & 2003 & $\begin{array}{l}\mathbf{1 . 1 4 7} \\
(0.012)\end{array}$ & $\begin{array}{l}1.986 \\
(0.042)\end{array}$ & $\begin{array}{l}1.533 \\
(0.024)\end{array}$ & $\begin{array}{c}0.77 \\
(0.011)\end{array}$ \\
\hline
\end{tabular}


On average, the differences between the observed prices and the synthetic prices are positive. Considering the two larger generators jointly, their bidding behavior has increased the average price by $0.77 \mathrm{c} € / \mathrm{kWh}$. In the appendix we present the same table for the smaller generators; UF, which has around $10 \%$ market share shows a slight positive impact on prices, when we compare its behavior with even smaller generators, while HC, with around 5\% market share, shows a negative impact on prices compared to the bidding behavior of $\mathrm{UF}$ and small generators.

The weighted average market power indexes are 


\begin{tabular}{|c|c|c|c|c|c|}
\hline \multirow[b]{2}{*}{$M P_{i}$} & \multirow[b]{2}{*}{ Period } & \multirow[b]{2}{*}{ All Hours } & \multicolumn{3}{|c|}{ Type of Hour } \\
\hline & & & Peak & Off-peak 2 & Off-peak 1 \\
\hline \multirow{4}{*}{$\frac{\overline{P_{w}}-\overline{P_{w}} E N^{s}}{\overline{P_{w}}}$} & $2001-2003$ & 0.05 & 0.06 & 0.08 & 0.04 \\
\hline & 2001 & 0.05 & 0.04 & 0.01 & 0.06 \\
\hline & 2002 & 0.04 & 0.06 & 0.07 & 0.02 \\
\hline & 2003 & 0.08 & 0.07 & 0.15 & 0.06 \\
\hline \multirow{4}{*}{$\frac{\overline{P_{w}}-{\overline{P_{w}}}^{I B^{s}}}{\overline{P_{w}}}$} & $2001-2003$ & 0.22 & 0.31 & 0.23 & 0.2 \\
\hline & 2001 & 0.15 & 0.27 & 0.11 & 0.15 \\
\hline & 2002 & 0.11 & 0.22 & 0.11 & 0.10 \\
\hline & 2003 & 0.38 & 0.44 & 0.45 & 0.35 \\
\hline \multirow{4}{*}{$\frac{\overline{P_{w}}-{\overline{P_{w}}}^{E N^{s}+I B^{s}}}{\overline{P_{w}}}$} & $2001-2003$ & 0.25 & 0.36 & 0.27 & 0.23 \\
\hline & 2001 & 0.23 & 0.32 & 0.16 & 0.24 \\
\hline & 2002 & 0.13 & 0.23 & 0.14 & 0.10 \\
\hline & 2003 & 0.43 & 0.52 & 0.53 & 0.39 \\
\hline
\end{tabular}

According to these results, the behavior of the two larger firms at the auction has increased prices jointly by $25 \%$ and IB's bidding behavior is responsible for a much larger increase than EN's. This is in contrast witht the fact that EN has a higher market share and higher capacity than IB.

This difference between the two larger firms could be explained by several factors. The electricity market is vertically integrated so that EN and IB own firms on the demand side. Hence, their incentives to raise prices could be de- 


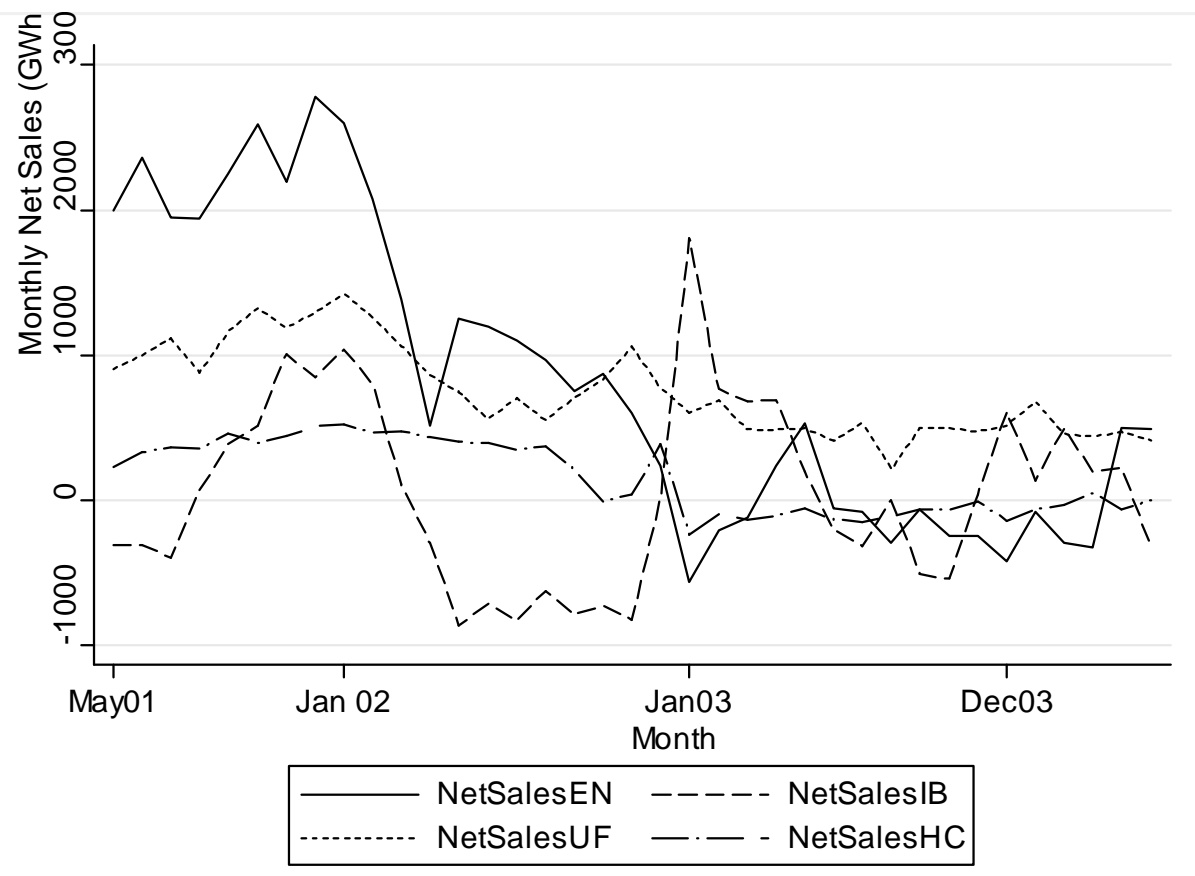

termined by whether they are net buyers or net sellers. A company which is a net buyer with high frequency would have lower incentives to raise prices (see a recent paper by Kuhn and Machado (2004) who look at the consequences of the vertical structure in this market). ${ }^{19}$ We have calculated the monthly net selling position for the different firms from 2001 to $2003 ;^{20}$ Figure 2 shows the results for each company, whereas Figure 3 shows the difference between EN and IB's net selling positions.

If the vertical structure were the explanation for the lower EN's price cost margins in generation we should observe that EN's selling position is consistently

\footnotetext{
${ }^{19}$ We thank Matilde Machado for suggesting this explanation.

${ }^{20}$ Distribution is regulated, so we have attributed to each firm the percentage in which the participate in the profits of the distribution companies (see appendix for a more detailed explanation.
} 


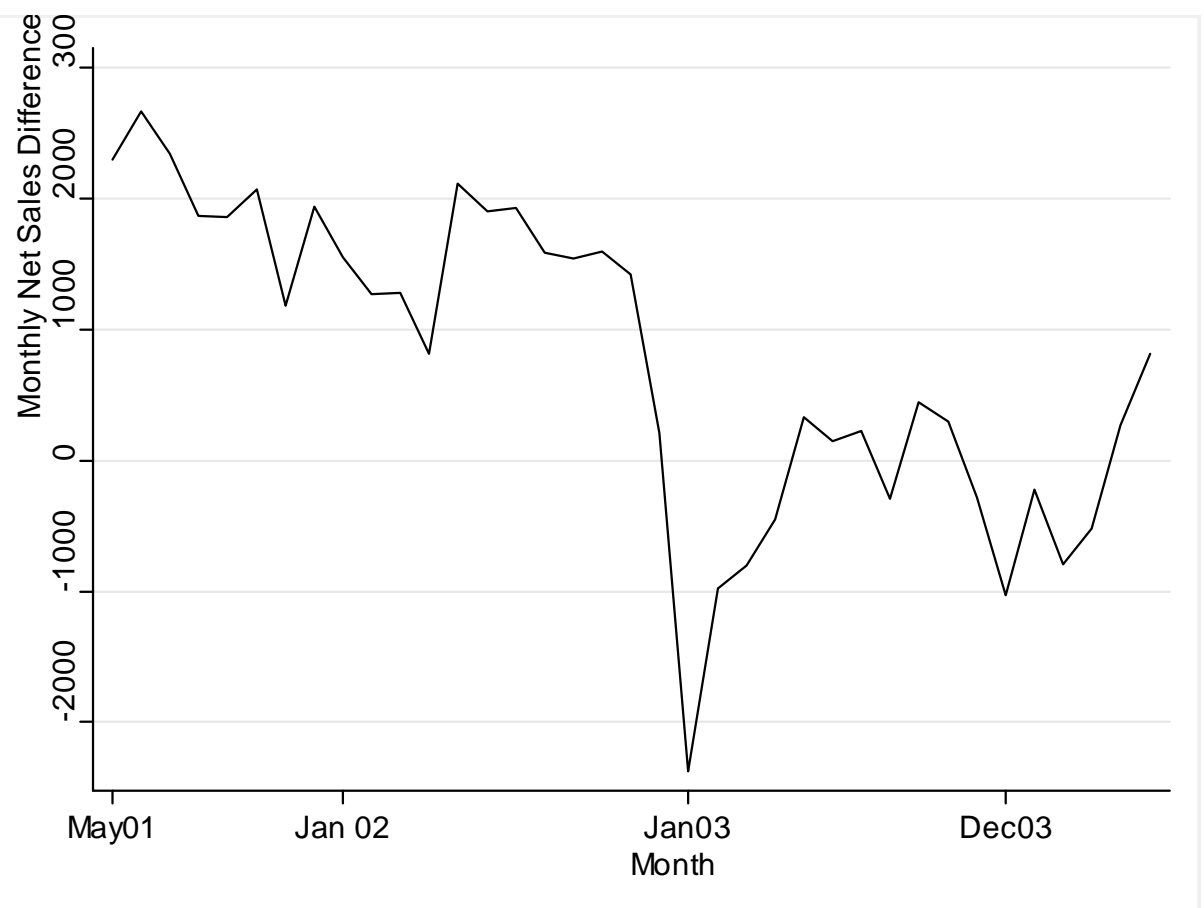

lower than IB, but as shown in Figure 3 this is not the case in the period 20012003.

Regulation concerning the payment of Competition Transition Charges (CTCs) is very likely to be the driving force behind the bidding behavior at the pool. The right to collect these payments for the recovery of stranded costs is lost (or partially lost) if the final weighted average price perceived by the generators goes above a reference price $(3.606 \mathrm{c} € / \mathrm{kWh}) .^{21}$ Generators' incentives differ depending on each firm's entitlement to these CTCs' payments. A firm with a high percentage of these payments to recover has a lower incentive to increase

\footnotetext{
${ }^{21}$ Several authors have pointed out this effect of CTCs; see, for example, Lasheras (1998) and García Martín (2001). IB and Gas Natural have declared that CTCs are behind EN bidding behavior (El Correo Digital, July 29, 2004)
} 
the pool price. The percentages for 2001 were are as follows: EN: 50.36\%; IB: 24.63\%; UF: 13.29\%; HC: 6.35\%; Elcogás: 3.45\% and Viesgo:1.92\%. Thus, IB, with a relatively low share of CTCs compared to its market share has a stronger incentive to restrict output. This is consistent with the empirical evidence presented here.

\section{Conclusions}

We have compared the bidding behavior at the pool of technologically similar plants, ones under the ownership of larger generators and the others under the ownership of smaller firms. Any systematic difference in their bid schedules could be attributed to the market power of larger generators. We have observed this different behavior in terms of bidding curves at the pool and measured the impact on equilibrium prices.

There are differences in bidding behavior between larger and smaller generators in the Spanish wholesale market. Given that demand is very inelastic and supply highly concentrated, larger generators would be able to increase prices by a considerable amount. There are however, mitigating forces for this potential market power. Vertical integration may alter the incentives to raise prices since generators are also important buyers at the pool. However, vertical integration alone does not seem to explain why IB has a higher price cost margin than EN.

Regulation concerning the recovery of stranded costs (CTCs) provides incentives not to raise prices above a reference price set by the regulator. Further- 
more, it provides different incentives for different generators, depending on their share on the CTCs payments. This is consistent with the empirical evidence concerning the bidding behavior of the two larger generators at the pool.

The possibility of collusion has been ignored. It is possible that part of the market power that we measure in this paper is due to the repetition of the auction, which would allow firms to sustain outcomes which are more cooperative than the one-shot outcome. It is difficult to empirically distinguish between the impact of collusion and the effect of 'static' market power. The analysis of collusion would require further work and is left for future research. Other important issues omitted include capacity choice (see Castro, Marín and Siotis (2001). Finally, an interesting question will be the analysis of the changes in bidding behavior after the introduction of the Iberian market (MIBEL). 


\section{References}

Bolle, F. (1992) Supply Function Equilibria and the Danger of Tacit Collusion: The Case of Spot Markets of Electricity, Energy Economics, 14(2), p. 94-102.

Baldick, R., R. Grant and E. Kahn, 2000, Linear Supply Function Equilibrium: Generalizations, Applications, and Limitations, UCEI Working Paper PWP-078.

Borenstein, S., J. B. Bushnell, and F. A. Wolak, 2002, Measuring Market Inefficiencies in California's Restructured Wholesale Electricity Market, The American Economic Review 92, 5, p. 1376-1405.

Borenstein, S., J. Bushnell, and F. Wolak, 2000, Diagnosing Market Power in California's Deregulated Wholesale Electricity Market, UCEI Working Paper PWP-064.

Bushnell, J., 1998, Water and Power: Hydroelectric Resources in the Era of Competition in the Western U.S.” POWER Working Paper PWP-056, University of California Energy Institute.

Bushnell, J and C. Saravia, 2002, An Empirical Assessment of the Competitiveness of the New England Electricity Market, University of California Energy Institute, CSEM WP-101.

Castro-Rodriguez, F., P. Marín and G. Siotis, 2001, Capacity Choices in Liberalized Electricity Markets, CEPR Discussion Paper \# 2998.

Fabra, N., 2001, Market Power in Electricity Markets, Ph. D. thesis, Department of Economics, European University Institute, Florence.

Fabra, N., 2003, Tacit Collusion in Repeated Auctions: Uniform versus Dis- 
criminatory, The Journal of Industrial Economics 51, p. 271-294.

Fabra, N., von der Fehr and Harbord, 2002, Modeling Electricity Auctions, The Electricity Journal.

García-Díaz, A. and Marín, P., 2003, Strategic Bidding in Electricity Pools with Short-Lived Bids: An Application to the Spanish Market, International Journal of Industrial Organization 21, 2, p. 201-222.

García Martín, J. A., 2001, Spot Market Competition with Stranded Costs in the Spanish Electricity Industry, WP 0106, CEMFI.

Green, R. and D. Newbury, 1992, Competition in the British Electricity Spot Market, Journal of Political Economy 100, 5, p. 929-953.

Green, R., 1994, Britain's Unregulated Electricity Pool, From Regulation to Competition: New Frontiers in Electricity Markets. M. Einhorn ed., Boston, Ma: Kluwer, p. 73-96.

Green, R., 1996, Increasing Competition in the British Electricity Market, Journal of Industrial Economics 44, p. 205-216.

Green, R., 1999, The Electricity contract market in England and Wales, The Journal of Industrial Economics 47, 1, p.107-124.

Green, R., 2001, Failing Electricity Markets: Should we shoot the Pools?, CEPR Discussion Paper 3015, October 2001.

Klemperer, 2002, What Really Matters in Auction Design, Journal of Economic Perspectives 16, 1, p. 169-189.

Kühn, K.-U. and M. Machado, 2004, Market Power and Vertical Integration in the Spanish Electricity Market. Universidad Carlos III de Madrid, mimeo. 
Lasheras, M. A. ,1998, Stranded costs in the Spanish electricity industry, Madrid, CNSE (http://www.cne.es)

Lerner, A. P., 1934, The Concept of Monopoly and the Measurement of Monopoly Power, Review of Economic Studies, June, p. 157-175.

Macatangay, R.E.A., 2002, Tacit Collusion in the Frequently Repeated MultiUnit Uniform Price Auction for Wholesale Electricity in England and Wales, European Journal of Law and Economics 13, 3, p. 257-273.

Mount, T., 2001, Market Power and Price Volatility in Restructured Markets for Electricity, Decision Support Systems 30, 3, p. 311-325.

Nevo, A., 2001, Measuring Market Power in the Ready-To-Eat Cereal Industry, Econometrica 69, 2, p. 307-342.

Newbury, D. M., 2002, Problems of liberalizing the electricity industry, European Economic Review 46, p. 919-927.

Ocaña, C. and A. Romero, 1998, Una Simulación del Funcionamiento del Pool de Energía Eléctrica en España, Documento de Trabajo DT 002/98, CNSE.

Spear, S. E., 2003, The Electricity Market Game, Journal of Economic Theory 192,2 , p. $300-323 .$.

von der Fehr, N.-H. M. and D. Harbord, 1993, Spot Market Competition in the UK Electricity Industry, Economic Journal, 103, 418, p. 531-546.

Wang J. J. D. and J. F. Zender, 2002, Auctioning Divisible Goods, Economic Theory 19, 4, p.673-705.

Wolfram, C., 1999, Measuring duopoly power in the British electricity spot market, The American Economic Review, 89, 4, p. 805-827. 
Wolfram, C., 1998, Strategic Bidding in a Multi-Unit Auction: An Empirical Analysis of Bids to Supply Electricity in England and Wales, Rand Journal of Economics 29, 4, p. 703-725.

OMEL Electricity Market Activity Rules, April 2001. 


\section{Appendix 1. The system marginal price}

The equilibrium price is the price obtained from the intersection of aggregate demand and aggregate supply curves. At the Spanish pool that price is calculated as follows (see OMEL's Electricity Market Activity Rules):

The marginal price shall correspond to the price of the last block of electric power supply offered for sale submitted by the last production unit whose acceptance was necessary to satisfy the matched demand. The market operator shall accept, at the marginal price, the total electric power offered in those sale bids whose prices are below the marginal price. The market operator shall accept, at the marginal price, the total electric power demanded by buyers in all the electric power purchase bids whose maximum prices are above the marginal price, except in cases where there is not enough electric power at prices that are lower than or equal to the marginal price to satisfy the demand that incorporates prices that are higher than the marginal price.

If there is excess supply at the marginal price, it shall be proportionately deducted from the sales of those units whose price is equal to the marginal price. If there is excess demand at the marginal price, it shall be proportionately deducted from the quantities of electric power included in the blocks of those purchase bids whose price is equal to the price of the last accepted purchase bid.

When demand and supply cross in a vertical section of the supply curve, according to these rules the marginal price is lower than the market clearing price. 


\section{Appendix 2. Building a Synthetic Firm}

We consider the electricity market auction on June 28th, 2001, at 18:00 hours. Puentes Garcia Rodriguez 2 (Code PGR2), is a generation unit that belongs to Endesa (EN). It uses lignite and imported coal as input. The plant which is closest in technical characteristics is Meirama 1, (code MEI1), which belongs to Unión Fenosa (UF). Table 5 below shows the way we build the Synthetic PGR2, $P G R 2^{S}$. The first column is the block number corresponding to the plants bids. Column 2 is the price bid, column 3 is the quantity bid and column 4 gives the points (price,quantity) in the bid schedule. In the synthetic PGR2 there are as many blocks as in MEI1 (that is, two in this example) and the quantities are proportinal to the capacity of PGR2.

Table 3 . Building Synthetic PGR2 (EN)

\begin{tabular}{|l|l|l|l|l|l|l|l|l|l|}
\hline & \multicolumn{3}{|c|}{ PGR2 bids } & \multicolumn{3}{|c|}{ MEI1 bids } & \multicolumn{3}{|c|}{ SyntheticPRG2 bids } \\
\hline & Pr & Qu & Bid Schedule & Pr & Qu & Bid Schedule & Pr & Qu & Bid Schedule \\
\hline Block 1 & 0 & 216 & $(0 ; 216)$ & 0 & 532 & $(0 ; 532)$ & 0 & 331.65 & $(0 ; 331.65)$ \\
\hline Block 2 & 1.192 & 19 & $(1.192 ; 235)$ & 15 & 31.2 & $(15 ; 563.2)$ & 15 & 19.45 & $(15 ; 351.1)$ \\
\hline Block 3 & 1.283 & 106.1 & $(1.283 ; 341.1)$ & & & & & & \\
\hline Block 4 & 9.9 & 9.9 & $(9.9 ; 351)$ & & & & & & \\
\hline Capacity & & & 351 & & & 563.2 & & & 351.1 \\
\hline
\end{tabular}




\section{Appendix 3}

Table 4. Test of Means for Smaller Generators

\begin{tabular}{|c|c|c|c|c|c|}
\hline \multirow[b]{2}{*}{$\mathrm{c} € / \mathrm{kWh}$} & \multirow[b]{2}{*}{ Period } & \multirow[b]{2}{*}{ All Hours } & \multicolumn{3}{|c|}{ Type of Hour } \\
\hline & & & Peak & Off-peak 2 & Off-peak 1 \\
\hline \multirow{8}{*}{$\bar{P}-\bar{P}^{U F^{s}}$} & & 0.161 & 0.138 & 0.178 & 0.155 \\
\hline & & $(0.002)$ & $(0.008)$ & $(0.004)$ & $(0.023)$ \\
\hline & 2001 & 0.116 & -0.050 & 0.108 & 0.143 \\
\hline & & (0.005) & $(0.026)$ & $(0.009)$ & $(0.005)$ \\
\hline & & 0.221 & 0.219 & 0.226 & 0.22 \\
\hline & & $(0.036)$ & $(0.012)$ & (0.007) & $(0.004)$ \\
\hline & & 0.128 & 0.153 & 0.177 & 0.096 \\
\hline & & $(0.003)$ & $(0.01)$ & $(0.006)$ & $(0.004)$ \\
\hline \multirow{8}{*}{$\bar{P}-\bar{P}^{H C^{s}}$} & בחקר & -0.262 & -0.656 & -0.029 & -0.215 \\
\hline & & $(0.033)$ & $(0.121)$ & $(0.072)$ & $(0.442)$ \\
\hline & 2001 & -0.412 & -0.836 & -0.019 & -0.558 \\
\hline & & $(0.037)$ & (0.137) & $(0.064)$ & $(0.047)$ \\
\hline & קח רחת & -0.120 & -0.342 & -0.689 & -0.306 \\
\hline & & $(0.055)$ & $(0.195)$ & $(0.1)$ & $(0.685)$ \\
\hline & 2003 & -0.301 & -0.881 & -0.38 & -0.885 \\
\hline & & $(0.038)$ & $(0.052)$ & $(0.063)$ & $(0.114)$ \\
\hline
\end{tabular}

